\title{
The grand coalition versus competing coalitions: trade-offs in how to standardize
}

Citation for published version (APA):

van Wegberg, M. J. (2003). The grand coalition versus competing coalitions: trade-offs in how to standardize. METEOR, Maastricht University School of Business and Economics. METEOR Research Memorandum No. 021 https://doi.org/10.26481/umamet.2003021

Document status and date:

Published: 01/01/2003

DOI:

10.26481/umamet.2003021

Document Version:

Publisher's PDF, also known as Version of record

\section{Please check the document version of this publication:}

- A submitted manuscript is the version of the article upon submission and before peer-review. There can be important differences between the submitted version and the official published version of record.

People interested in the research are advised to contact the author for the final version of the publication, or visit the DOI to the publisher's website.

- The final author version and the galley proof are versions of the publication after peer review.

- The final published version features the final layout of the paper including the volume, issue and page numbers.

Link to publication

\footnotetext{
General rights rights.

- You may freely distribute the URL identifying the publication in the public portal. please follow below link for the End User Agreement:

www.umlib.nl/taverne-license

Take down policy

If you believe that this document breaches copyright please contact us at:

repository@maastrichtuniversity.nl

providing details and we will investigate your claim.
}

Copyright and moral rights for the publications made accessible in the public portal are retained by the authors and/or other copyright owners and it is a condition of accessing publications that users recognise and abide by the legal requirements associated with these

- Users may download and print one copy of any publication from the public portal for the purpose of private study or research.

- You may not further distribute the material or use it for any profit-making activity or commercial gain

If the publication is distributed under the terms of Article $25 \mathrm{fa}$ of the Dutch Copyright Act, indicated by the "Taverne" license above, 


\title{
The grand coalition versus competing coalitions: trade-offs in how to standardize
}

\author{
Marc van Wegberg $\left.{ }^{*}\right)$
}

May 2003

\begin{abstract}
The standardization landscape in the Information and Communication technology industries is fragmented in many different standardization bodies, industry consortia, and alliances. Some of these coalitions cooperate with each other, while others compete. The existence of competing standardization coalitions may prevent coordination on a common standard. There is a lot of debate among practitioners and analysts about whether this fragmentation creates a coordination failure. This paper takes a middle ground in this debate. Competition between standardization coalitions may indeed harm compatibility, but it also helps to mitigate coordination failures within standardization bodies and coalitions. The negotiation process in a coalition can cause coordination failures of its own. An important failure is lack of timeliness, due to delaying tactics by company delegates in the coalition. Introducing competition between coalitions can speed up negotiations within them, and thus help to overcome this intracommittee coordination failure. A game theoretic model explores the effect of competition between coalitions on the speed of decision-making and standardization.
\end{abstract}

*) Assistant Professor, Faculty of Economics and Business Administration, University of Maastricht, P.O. Box 616, 6200 MD Maastricht, The Netherlands, tel. +31 43-3883654, fax. +31 43-3884877, e-mail: M.vanWegberg@os.UniMaas.nl, mvanwegberg@yahoo.com, home page: http://www.geocities.com/mvanwegberg/ . I thank my colleagues from the Infonomics institute in Maastricht for comments, the audience of the EURAS workshop in Wroclaw, June 2002, as well as colleagues Adrés Perea y Monsuwé and Hans de Graaff. 


\section{Introduction}

The standardization landscape in the Information and Communication technology industries is fragmented in many different standardization bodies, industry consortia, and alliances. Some of these coalitions cooperate with each other, while others compete. The existence of competing standardization coalitions may prevent coordination on a common standard. There is a lot of debate among practitioners and analysts about whether this fragmentation leads to coordination failures. A better understanding of why companies have standardization strategies that give rise to fragmentation may show the possible advantages of fragmentation.

Compatibility standards set specifications for components that make it possible to connect these components to each other. In the information and communication technology industries, the examples of these components are hardware and software. By connecting devices, end users can improve their performance (complementary products) or service providers can help their end users interact with each other. Standards create value when they make it possible to realize positive network externalities for the end users or for their suppliers. The standardization process can therefore be an important value-generating process. How this process is organized, the standardization mode, affects the outcome of the standardization process. Standardization processes are partly organized in coalitions. How many coalitions there are, and how many members each has, is known as the coalition structure of the standardization process (Bloch, 1995). An important aspect of the standardization mode is the level of centralization, defined here as the extent to which decision-making about standards is concentrated in one or more coalitions.

The most centralized coalition structure is the grand coalition: a coalition that includes all participants in the standardizing process. In the case of a standard that affects an industry, this will be an industry-wide coalition. The advantage of a grand coalition is that this level of coordination assures that a single standard will be established. As a result, technologies in use are fully compatible and positive network externalities can be realized. Other standardization modes are more decentralized. In many cases there are competing coalitions. Many standardization processes are highly fragmented as a result (Genschel, 1997). If competing coalitions set different, incompatible, standards, some network externalities will not be realized. How centralized the emerging coalition structure will be depends on the pros and cons of the various possible coalition structures. We will focus on the aspect of timing to highlight the pros and cons of coalition structures with different levels of centralization.

The grand coalition is the most centralized coalition structure. The rationale for a grand coalition is that all relevant parties will adopt the specifications (standards or recommendations) that it will develop. It has access to the widest number of players and their information. A consensual decision-making process means that specifications are accepted only if no none holds out against them. The consensus provides legitimacy to its specifications. Due to its comprehensive membership, information about the new standards is widely available in the field.

Choosing a standardization mode leads to trade-offs. One of these trade-offs is about the speed of decision-making. A grand coalition may have to comprise large number of participants. These may have many different backgrounds. There may be antagonistic organizations among them. These can slow down decision-making. One way to speed up decision-making is by excluding participants who would slow down decision-making. Participants with different or opposite interests may, for instance, be excluded from the coalition. Those who are excluded may go on to form their own committee (Axelrod, Mitchell, Thomas, Bennett, \& Bruderer, 1995; Belleflamme, 1998; Bloch, 1995; Economides \& Flyer, 1998; Greenlee \& Cassiman, 1999). For instance, Bloch (1995) argues that the more firms are direct rivals, the more tempted they are to exclude rivals from their coalition. The better substitutes their products are, the less likely that a grand coalition will appear, and the more likely that rivals establish competing committees. If competing committees are formed, they may accept different, incompatible technologies as a standard. 
This argument leads to a circumscribed defense of fragmentation. A grand coalition has a better chance of ensuring compatibility between the technologies used in an industry than competing coalitions. The higher the degree of compatibility between the technologies actually adopted by service providers, the more service providers can realize positive externalities. A grand coalition may also take more time to arrive at a decision than competing coalitions. It may fall prey to delaying tactics by delegates of competing firms. This delay represents an intracoalition coordination failure. The smaller size of competing coalitions, and the competition between them, tend to speed up their decision-making. This greater speed does come at the possible risk of selecting incompatible technologies, which generates an inter-coalition coordination failure. How this trade-off between speed and compatibility affects the degree of centralization in the coalition structure is the topic of this paper.

The paper consists of two parts. It begins with a review of the literature. The review concludes with a conceptual model of the selection of coalition structures for standardization. A game theoretic model subsequently explores the basic assumptions and possible results of this conceptual model.

\section{The trade-off between timing and coordination}

Two questions motivate this paper. First, does the menu of possible coalition structures confront firms with a trade-off between timing and compatibility? There will be a trade-off if the more a coalition structure succeeds in raising the degree of compatibility between different technologies, the longer its standardization process takes. And, secondly, if there is this trade-off, how does it affect the preferences firms may have for possible coalition structures? If there are potential network externalities, firms will derive value from compatibility. Establishing compatibility requires the selection of standards, which takes time. Firms are willing to give up some compatibility for the sake of speeding up the selection of standards. The more important compatibility is to them, the more they are willing to give up some speed of decision making.

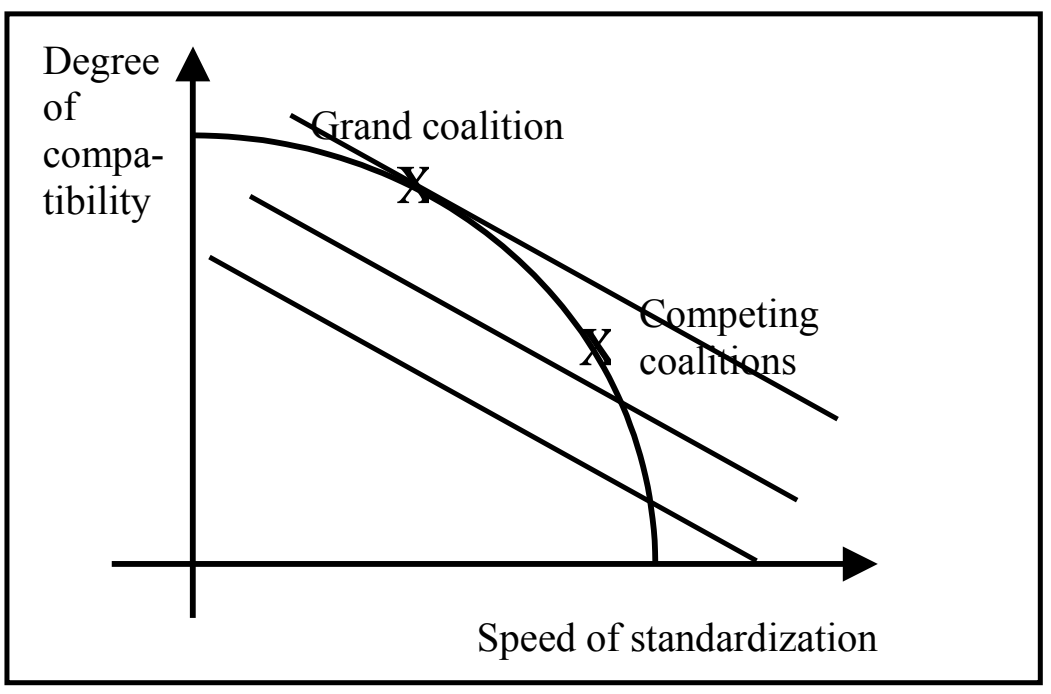

Figure 1: the trade-off between timing and the degree of compatibility

Figure 1 combines the two aspects of the trade-off. The concave curve combines all combinations of the degree of compatibility and the useful lifetime that can be achieved with the existing set of standardization modes. This curve will be concave if the more centralized the coalition structure is, the higher the degree of compatibility that it tends to be able to achieve, at a cost of a slower 
standardization process. The straight lines in figure 1 are payoff indifference curves: combinations of the degree of compatibility and speed of standardization that offer the same benefit to the firm. ${ }^{1}$ If, for example, the degree of compatibility has a relatively large effect on revenues, a firm is willing to give up some compatibility only in exchange for a large increase in the speed of standardization. This suggests a small compatibility / lifetime slope in figure 1 . The further out the indifference curve is from the origin, the higher the level of payoffs it represents. A firm will prefer the coalition structure (a point on the concave curve) that lies on its highest located indifference curve (straight line). If, as illustrated in figure 1, a firm is willing to give up very little compatibility for the sake of speeding up standardization (a barely sloped indifference curve), this suggests a preference for a centralized standardization mode, such as the grand coalition.

For an individual firm, the preference for a standardization mode boils down to the question how much compatibility it is willing to give up for a higher speed of the standardization process (the straight lines), and which standardization mode best fits this preference (the concave curve). Figure 1 represents a situations where two propositions apply: first, that coalition structures cause a trade-off between speed and compatibility, and second, that firms are willing to trade in some speed of standardization for the sake of greater compatibility. We will investigate both propositions in sequence.

\section{Trade-offs caused by the standardization mode}

The first question to address is how coalition structures affect the degree of compatibility that can be achieved, and the speed of standardization. The proposition we wish to explore is that the higher the level of centralization of a coalition structure, the higher the chance that it generates compatibility at industry level, and the longer standardization tends to take.

\section{Centralization and speed of standard selection}

The first impact of a coalition structure is that the more inclusive an individual coalition is, the longer it takes to agree on a standard. There is an initialization phase to a partnership (Zajac \& Olsen, 1993). In this initialization phase, firms communicate, negotiate, analyze feasibility studies, and forge relational exchange norms. Which factors can facilitate this process? One factor will be the size of the coalition. The more members in a committee, the more alternative technologies there may be to choose between. Communication takes time. The more people are involved, the more time it takes to communicate with them. If participants have different backgrounds, it can take time to translate concepts between them. They will need to develop a common vocabulary. In the Internet tradition, for example, participants in a standardization process will often need to define concepts first, using a document type called a Request for Comments, RFC. An example is RFC 2119 of the Internet Engineering Task Force (IETF), which defines among others the meaning of concepts such as must, must not, shall, etc., when used in standards. ${ }^{2}$

There are factors that may shorten the initialization phase. Prior contacts between the partners can facilitate the set-up of a partnership. This may explain an insight about partner choice in strategic alliances: firms with prior contacts are more likely to become partners in an alliance (Gulati, 1995).

The political process in a grand coalition may slow down decision-making. The sponsor of a specific standard may take time to influence the grand coalition. A sponsor is a firm that

\footnotetext{
${ }^{1}$ Where payoffs are defined in terms of the goals that firms pursue, such as profits, cash flow, growth, market share, etc.

${ }^{2}$ See http://www.ietf.org/rfc/rfc2119.txt for this RFC (Nov. 2002). Note that an RFC is a standard, in the language of the IETF.
} 
actively supports a particular specification for a standard through a standardization process. It is likely to be a firm that expects more benefits from a successful standardization process than most other participants. It is, for example, the innovator who developed the technology that can be standardized. If multiple sponsors jockey for position in a grand coalition, they may slow down the process of creating consensus and selecting a standard.

A sponsor may try to win over the grand coalition by actively participating in its activities. Organizations may invest in influencing activities to influence the coalition's decision making (Besen \& Farrell, 1994). In the ICT industries, for instance, sponsors influence official standardization bodies by means of the contributions they make to the work of these bodies. An interesting paper observes that large companies increased the number of staff they dispatch to meetings of official organizations, such as the IETF and the IEEE (the Institute of Electrical and Electronics Engineers) (Heywood, Jander, Roberts, \& Saunders, 1997). They hire people who have gained influence and reputations in official standard setting organizations. They also try to influence who will chair workgroups of standardization organizations. As Heywood et al. (1997) show, standardization organizations are aware of these possibilities, and try to design rules to suppress them.

Rules and procedures in standardization coalitions may suppress dysfunctional behavior of individual participants. They may also diminish the influence of these participants. As a result, these firms may abandon the coalition and set up competing coalitions. In a decentralized standardization mode with multiple competing coalitions, an individual firm has a larger chance of influencing its particular coalition. But there is the real chance that having competing coalitions leads to incompatible technologies being used in the market place. A grand coalition may want to prevent defection by being very responsive to the interests of its members. Too much responsiveness may bog down the standardization process (Sherif, 2003). Hence, a grand coalition faces some tension between speeding up decision making and ensuring compatibility of new technologies.

Grand coalitions such as formal standard setting bodies know they need to speed up decision-making (David \& Shurmer, 1996). One of the solutions is to produce incomplete standardization by means of meta-standards. A meta-standard establishes some conditions and aspects of a standard, without specifying the standard itself in full detail. Settling details of a standard can take a lot of time. Setting a meta-standard avoids the need to fine-tune the standard, and thus speeds up decision making. The advantage of having a meta-standard in an early stage is that it pre-empts companies that might otherwise commit to incompatible technologies. A disadvantage of setting a meta-standard is that private companies adopt technologies that are only partially standardized. Their technologies may be partially incompatible. This solution therefore gives up some compatibility in order to speed up decision making in a grand coalition.

\section{Centralization and compatibility}

A second impact of coalition structure is that more centralized it is, the more likely that a single standard prevails. In particular, a grand coalition is more likely to adopt a single standard than competing coalitions. A grand coalition can select a standard from among competing technologies. It may also try to combine different technologies into a compromise standard. The DVD standard is the result of such a compromise. ${ }^{3}$ The DVD consortium combined the multimedia CD coalition of Philips, Sony, and 3M, with the super density CD of Toshiba and Time Warner. The combination gave rise to the DVD specification, albeit after specification and format disagreements in the DVD consortium delayed the introduction of DVD products. A grand coalition or industry-wide standard development organization can also design specifications to

\footnotetext{
${ }^{3}$ Source: Aguilar, Rose (1996) Philips, Sony team to hurry up DVD, Cnet, http://news.com.com/21021023-219879.html, August 2, 1996.
} 
reduce incompatibility. For example, the IEEE has developed several standards for wireless data communication. Some of these technologies use the same unlicensed frequency band. As a consequence, wireless systems can interfere. Interference can diminish the quality of the signal. The IEEE developed standards for Wireless Local Area Networks and Wireless Personal Area Networks that reduce the disadvantages of interference. ${ }^{4}$

A grand coalition will not always be able to ensure compatibility when its members simultaneously play a game of de facto standardization. Participants in the grand coalition may try to create a fait-a-compli to force the coalition to bend to its wishes. A firm may start an installed base with its technology in an attempt to strengthen its bargaining power in the coalition. This leads to hybrid standardization: a standardization mode where firms pursue standardization by two simultaneous paths, using both the market mechanism and negation in the committee (Axelrod et al., 1995; Farrell \& Saloner, 1988; Funk \& Methe, 2001). In a hybrid standardization mode, a grand coalition cannot guarantee compatibility. The best way to prevent incompatibility in this case is for the grand coalition to agree on a standard fast, before some of its members have committed themselves to a de facto standard. A hybrid standardization mode may thus speed up standardization, but at a cost (Farrell \& Saloner, 1988). The cost may be that companies adopt incompatible technologies.

While the grand coalition may not guarantee compatibility, the presence of competing coalitions need not per se lead to incompatibility. If one committee adopts a standard quickly, the members of a competing coalition may adopt that standard (Genschel, 1997). In this case they abandon the slowest committee. Furthermore, competing committees make choices that do not have to be entirely incompatible. They may adopt partially overlapping technologies, leading to partial compatibility. In his book about Bill Gates, Wallace (1997) gives a more controversial example, when he attributes to Microsoft the strategy of embrace and extend. This strategy confronts a successful technology of a rival not by developing an incompatible alternative. Instead, the embrace and extend strategy is to adopt the technology, and then to extend it with proprietary extensions. ${ }^{5}$ Once users adopt these extensions, control over the technology shifts to Microsoft. Competing coalitions may have the same motive to adopt partially or wholly a rival committee's technology. As a result, in a setting of competing coalitions, committee standards can be hybrids that combine elements from competing technologies (for an example, see Mangematin \& Callon, 1995).

If standardization coalitions or organizations cannot avoid incompatible technologies, they can design standards such as to make it possible to have gateways between incompatible technologies. For example, the IETF and the ITU (the International Telecommunications Union) cooperated to develop the Megaco/H.248 gateway protocol to act as gateway between dissimilar networks. ${ }^{6}$

To conclude this discussion. It is likely, but by no means certain, that a grand coalition takes more time to conclude a standard than smaller competing coalitions would. It is, moreover, not self evident that a grand coalition ensures a higher degree of compatibility than competing coalitions would. If not, a grand coalition is unlikely to occur. In that case the choices of individual organizations boil down to which competing coalition to join. Only when a grand

\footnotetext{
4 Source: IEEE, http://www.ieee.org, Steve Shellhammer (2001) IEEE 802.15.2 Clause 5.1 Description of the Interference Problem, July 2, 2001.

${ }^{5}$ There is debate about whether this strategy is legal. Judge Motz of the U.S. district court in Baltimore ordered Microsoft to include Sun Microsystems' version of Java with the Windows operating system (Cnet, http://news.com.com/2102-1001-978786.html, Dec. 23, 2002). The verdict is a response to Sun's suing Microsoft 'for allegedly violating antitrust law in dropping Sun's version of Java and including its own version, which Sun alleges to be incompatible with its technology.'

${ }^{6}$ Source: IETF, 18-2-2002, http://www.ietf.org/html.charters/megaco-charter.html, and IETF, Request for Comments: 2805, April 2000, http://www.ietf.org/rfc/rfc2805.txt.
} 
coalition compensates for a longer duration of decision making by increasing the expected degree of compatibility, do firms face the trade-off depicted in figure 1.

\section{Effects of the standardization mode on firm goals}

If we accept that coalition structures represent different trade-offs between compatibility and speed of decision making, the next question that presents itself is: how do compatibility and speed in turn affect the ability of firms to realize their goals? The slope of the indifference curves in figure 1 depends on the relative effects of the degree of compatibility and of speed of standardization on the payoffs of the firm. There are thus two links to consider: the link between compatibility and payoffs, and the link between speed of standardization and payoffs.

\section{Compatibility, payoffs, and strategy}

The first link to look at is the link between the degree of compatibility and the payoffs of the organizations involved in standardization. An open industry-wide standard can be a platform for new services. This applies to anticipatory standards, which are standards for new technologies that will develop new services and associate markets (Sherif, 2003). There are direct network externalities if new services enable users to communicate with each other. The more users can communicate with each other, using standards-compliant equipment, the more benefits they derive from participating in the new service. This is how a standard can create value. The higher the degree of compatibility between the technologies used by vendors, the greater the value created in the product market (Katz \& Shapiro, 1985).

There may be reasons both on the demand side and on the supply side that reduce the value-creating effect of an industry-wide standard. If users tend to communicate in small communities, the sheer size of the network of users may not increase their benefit. As long as a standard dominates within their particular community, they may not care about standards used by other communities. A study by Cowan and Miller (1998) offers support for this intuition. It studies a case with local externalities, where neighbors are potential adopters of a standard to communicate or cooperate with each other. It finds that users may adopt incompatible technologies. Since they communicate locally, they are not aware (and do not care) of far away users adopting a different technology.

If there are potential network externalities in a product market, service providers may try to achieve them even if there is no standard. They may find other ways to achieve the network externalities. They can start gateway services that connect users of incompatible technologies. Converters link the users of otherwise incompatible technologies. They help these users to achieve positive externalities (Choi, 1996). There are thus several factors, both on the demand side and the supply side, that can reduce the value generating effect of a standard.

Even if compatibility is valuable for the market as a whole, individual firms may still find it in their interest to reduce the compatibility with other technologies. Negotiating a standard may affect the payoffs of firms in adverse ways. A sponsor may have intellectual property rights on the technology. A grand coalition may cause a sponsor to loose revenues from its property rights on the technology to be standardized. Submitting a technology to a Standard Development Organization (SDO) can limit the revenues from intellectual property rights (IPR) protection as the technology to be standardized has to be licensed to all takers on fair and reasonable terms. Grand coalitions can and sometimes do impose the same condition. Innovators may benefit if their innovation is accepted as a standard. They also want to earn revenues from their intellectual property rights on the innovation. They are concerned about the appropriability of revenue streams. They may care more about their share of the revenue stream from a standard than about the absolute size of revenues created by the standard. Patents are a case in point; they give the innovator some control over revenue flows generated by the innovation. If a standard increases 
the value of the intellectual property right (IPR) on a technology, the firm may be more interested in supporting one particular technology than in having an industry-wide standard per se. A concern with intellectual property rights on technologies may lead to fragmentation of the standardization process. Blind (2001) finds empirical support for the argument that patent protection may make companies reluctant to set standards via national or international standard setting organizations (SDOs).

There are thus various reasons why compatibility may not be valuable for the market as a whole, or at least for some players in it. In these cases a grand coalition, whose main job is to establish industry-wide standards, is not a likely channel for standardization.

\section{Speed, timing, and payoffs}

The second link to look into is the link between the timing aspect and the payoffs of the participants in standardization. How important is the time to market for the participants in the standardization process? If there are first move advantages, firms are likely to disagree with a time-consuming decision process in a committee. If, however, there are second move advantages, there is a benefit to waiting, and speeding up standardization may not be a priority at all. If technology improves continually, for example, users may switch to an incompatible technology if its quality is sufficiently higher than the established technology (Katz \& Shapiro, 1992; Shy, 1996). Shy (1996) shows among others that if new technology is backward compatible with the old technology, users are more likely to switch to the new technology. This reduces the lifetime of the older technology. The lifetime of a standard thus depends on the willingness of users to wait for better technology to appear.

Speeding up standardization will be valuable if the benefits from the standard are timedependent. The standard is a specification for a technology. There are expectations about when the technology will be superseded by a superior technology. Technologies have a lifecycle; the more time in this cycle is absorbed the standardization process, the less time remains for using it in marketable products. A standard may be a platform for new or improved services. These services themselves have a product life cycle. Delaying the product introduction delays the start of revenues. Due to the time preference of the potential vendors, they are likely to want to speed up market introduction.

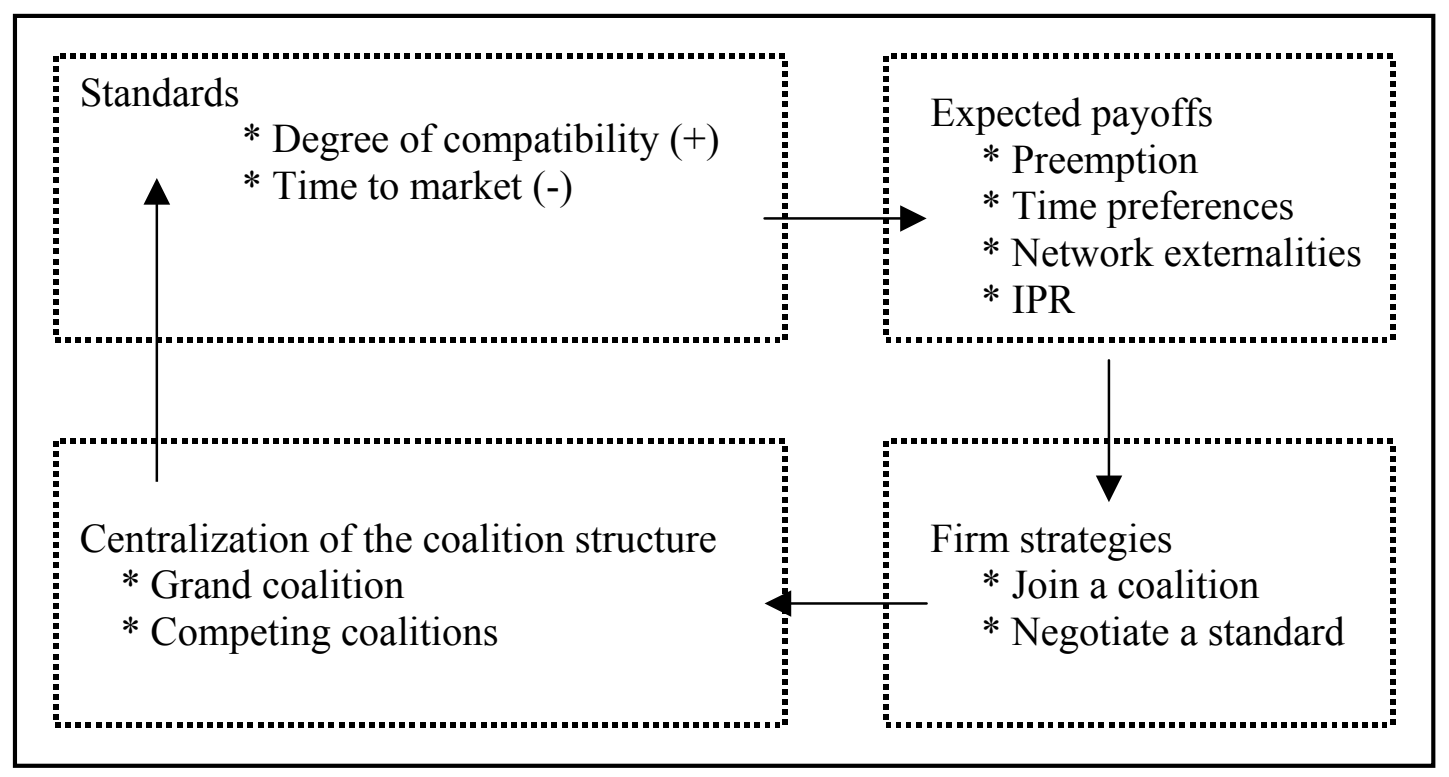

Figure 2: Choice of coalition structure in the trade-off between speed and compatibility 
Figure 2 summarizes the relationships discussed so far. If firms have different preferences for the standardization mode, a battle ensues about the standardization mode itself (Besen \& Farrell, 1994). Their strategies, the coalition structures they give rise to, and the competition in the product market, determine the actual standardization mode. The next section presents a model that shows how the interactions in figures 1 and 2 play out.

\section{Selecting a standardization mode: a basic model}

The literature is thus able to identify the expected effects that the standardization mode has on both the degree of compatibility that will result, and on the speed of standardization. It also identifies how these effects influence the ability of the individual firm to achieve its goals. What do these insights tell us about which standardization mode will actually occur? This outcome depends on the interaction between firms, taking into account the relationships discussed above. We develop a basic model to explore this. It is based on the seminal paper by Farrell and Saloner (1988).

In the model firms may form a grand coalition for an industry-wide standard, or they split up in competing groups. There are two technologies to choose from, 1 and 2. Firm 1 is sponsor of technology 1 and firm 2 is sponsor of technology 2. Firms 3 and 4 are indifferent between these two technologies; they do benefit from having a standard. If there is one standard, each firm earns a compatibility bonus $c$. In addition, the sponsor of the technology that is selected as standard earns the appropriability bonus $a$. If there are two competing technologies, each sponsor earns the appropriability benefit $a$; the other two firms earn zero payoffs. The appropriability bonus $a$ captures among others the importance of intellectual property rights on technology. The compatibility bonus $c$ captures the importance of positive network externalities for the expected payoffs.

\section{Competing committees}

With competing committees, each committee negotiates internally for a standard. We assume that each committee consists of a sponsor and a non-sponsor. Committee 1 consists of firms 1 and 3, while committee 2 consists of firms 2 and $4 .^{7}$ Each firm in a committee chooses between accepting the sponsored technology as standard and the option to wait. Waiting implies the option to accept the technology of a rival firm as standard. Call $\gamma_{\mathrm{i}}$ the chance that committee i selects the technology of its sponsor as standard in this period. If both committees select a standard simultaneously, the competition between the two standards eliminates the expected payoffs of the firms. If one committee selects a standard and the other does not, the latter adopts the standard of the former committee. The payoff matrix in committee 1 is:

\begin{tabular}{|c|c|c|c|}
\hline \multicolumn{4}{|c|}{ Table 1: committee 1 session and payoffs } \\
\hline & & \multicolumn{2}{|c|}{ (1) } \\
\hline & & T1 & Wait \\
\hline Firm 1 & $\mathrm{~T} 1$ & $\left(a+\left(1-\gamma_{2}\right) c,\left(1-\gamma_{2}\right) c\right)$ & $\left(\mathrm{y}_{1}, \mathrm{y}_{3}\right)$ \\
\hline
\end{tabular}

\footnotetext{
${ }^{7}$ An alternative specification would be: two non-sponsors, firms 3 and 4, team up. They select a technology, join up with its sponsor, and set the standard. This would be the quickest way to get a standard. If, however, the sponsor left out introduces its technology independently, the ensuing technology competition destroys the compatibility bonus. With our assumptions an asymmetric coalition structure (firms 1,3, and 4 versus firm 2, for instance) is possible, but not efficient. It is possible, because the game here is purely about coordination: there is no other reason, such as the need to pool resources or market power, that requires firms to team up in a standardization coalition.
} 
\begin{tabular}{|l|l|l} 
Wait & $\left(\mathrm{y}_{1}, \mathrm{y}_{3}\right)$ & $\left(\mathrm{y}_{1}, \mathrm{y}_{3}\right)$ \\
\hline
\end{tabular}

The expected payoffs of this game are $\left(\mathrm{U}_{1}, \mathrm{U}_{2}, \mathrm{U}_{3}, \mathrm{U}_{4}\right)$. The wait option defers results to the next period. This means to either accept the rival committee's selected standard, which it selected with a chance $\gamma_{2}$, or to adjourn the committee and play the game again in the next round. That is, $\mathrm{y}_{\mathrm{i}}=$ $\delta \mathrm{x}_{\mathrm{i}}$, where $\mathrm{x}_{\mathrm{i}}=\left(1-\gamma_{2}\right) \mathrm{U}_{\mathrm{i}}+\gamma_{2} \mathrm{c}(\mathrm{i}=1,3)$.

The mixed equilibrium for committee 1 leads to chance play. Firm 1 plays T1 with a chance $\alpha_{1}$ and wait with a chance of $1-\alpha_{1}$. Firm 3 plays T1 with a chance $\alpha_{3}$ and wait with a chance of $1-\alpha_{3}$. The expected payoffs of their game are:

$$
\begin{aligned}
& \mathrm{U}_{1}=\alpha_{1} \alpha_{3}\left(\mathrm{a}+\left(1-\gamma_{2}\right) \mathrm{c}\right)+\left(1-\alpha_{1} \alpha_{3}\right) \mathrm{y}_{1} . \\
& \mathrm{U}_{3}=\alpha_{1} \alpha_{3}\left(1-\gamma_{2}\right) \mathrm{c}+\left(1-\alpha_{1} \alpha_{3}\right) \mathrm{y}_{3} .
\end{aligned}
$$

The chance that committee 1 selects T1 as standard, $\gamma_{1}$, equals $\alpha_{1} \alpha_{3}$.

Firm 1 is indifferent between proposing T1 and waiting if the expected payoff of proposing $\mathrm{T} 1$ equals the expected payoff of waiting. This implies that $\alpha_{3}\left(\mathrm{a}+\left(1-\gamma_{2}\right) \mathrm{c}\right)+\left(1-\alpha_{3}\right) \mathrm{y}_{1}=$ $\alpha_{3} \mathrm{y}_{1}+\left(1-\alpha_{3}\right) \mathrm{y}_{1}$, where $\mathrm{y}_{1}=\delta\left(\left(1-\gamma_{2}\right) \mathrm{U}_{1}+\gamma_{2} \mathrm{c}\right)$, that is,

$$
\mathrm{a}+\left(1-\gamma_{2}\right) \mathrm{c}=\delta\left(\left(1-\gamma_{2}\right) \mathrm{U}_{1}+\gamma_{2} \mathrm{c}\right) .
$$

Firm 3 is indifferent if its expected payoff of selecting T1 equals its expected payoff of waiting. That is, $\alpha_{1}\left(1-\gamma_{2}\right) \mathrm{c}+\left(1-\alpha_{1}\right) \mathrm{y}_{3}=\alpha_{1} \mathrm{y}_{3}+\left(1-\alpha_{1}\right) \mathrm{y}_{3}$, where $\mathrm{y}_{3}=\delta\left(\left(1-\gamma_{2}\right) \mathrm{U}_{3}+\gamma_{2} \mathrm{c}\right)$. This gives:

$$
\left(1-\gamma_{2}\right) \mathrm{c}=\delta\left(\left(1-\gamma_{2}\right) \mathrm{U}_{3}+\gamma_{2} \mathrm{c}\right) .
$$

There are three possible equilibria. Case 1a occurs where both equalities (2a) and (2b) hold. Both firms are indifferent between playing T1 and waiting, both will play T1 with a certain chance, and T1 will be selected as standard with a positive chance. The equilibrium is $\left(\alpha_{1}, \alpha_{3}\right)$. Case 1a is a fluke case: conditions (2a) and (2b) both hold only in the special case where $a=\delta\left(1-\gamma_{2}\right)\left(U_{1}-U_{3}\right)$. With a $>0,0<\delta<1$, and $0<\left(1-\gamma_{2}\right)<1$, this gives a $<\mathrm{U}_{1}-\mathrm{U}_{3}$. The sponsor firm 1 would multiply its appropriability bonus $a$.

Two other cases occur when only one equality of (2a) and (2b) holds. In case $1 \mathbf{b}$, only equality (2b) holds: $\mathrm{a}+\left(1-\gamma_{2}\right) \mathrm{c}>\delta\left(\left(1-\gamma_{2}\right) \mathrm{U}_{1}+\gamma_{2} \mathrm{c}\right)$ and $\left(1-\gamma_{2}\right) \mathrm{c}=\delta\left(\left(1-\gamma_{2}\right) \mathrm{U}_{3}+\gamma_{2} \mathrm{c}\right)$; hence firm 1 always proposes $\mathrm{T} 1$ (its weakly dominant strategy) and firm 3 mixes between $\mathrm{T} 1$ and waiting. The equilibrium is $\left(1, \alpha_{3}\right)$. In case 1c, equation (2a) holds and $\left(1-\gamma_{2}\right) c>\delta\left(\left(1-\gamma_{2}\right) U_{3}+\gamma_{2} c\right)$. In this case, firm 1 is indifferent, and firm 3 always proposes T1. The associated equilibrium is $\left(\alpha_{1}, 1\right)$.

\begin{tabular}{|c|c|c|c|}
\hline & \multicolumn{2}{|c|}{ Firm 4} \\
\hline & & $\mathrm{T} 2$ & Wait \\
\hline \multirow[t]{2}{*}{ Firm 2} & $\mathrm{~T} 2$ & $\left.\left(a+\left(1-\gamma_{1}\right) c\right),\left(1-\gamma_{1}\right) c\right)$ & $\left(\mathrm{y}_{2}, \mathrm{y}_{4}\right)$ \\
\hline & Wait & $\left(\mathrm{y}_{2}, \mathrm{y}_{4}\right)$ & $\left(\mathrm{y}_{2}, \mathrm{y}_{4}\right)$ \\
\hline
\end{tabular}

The situation in committee 2 is similar, except that firm 2 is the sponsor, firm 4 the ally, and $\mathrm{T} 2$ the technology they may standardize on. See table 2 for the payoff table.

\section{Table 2: committee 2 session and payoffs}

The payoffs $y_{i}$ are $\delta\left(\left(1-\gamma_{1}\right) U_{i}+\gamma_{1} c\right)(i=2,4)$. As before, there are three possible equilibriums that depend on the following conditions:

$$
\mathrm{a}+\left(1-\gamma_{1}\right) \mathrm{c}=\delta\left(\left(1-\gamma_{1}\right) \mathrm{U}_{2}+\gamma_{1} \mathrm{c}\right) .
$$




$$
\left(1-\gamma_{1}\right) \mathrm{c}=\delta\left(\left(1-\gamma_{1}\right) \mathrm{U}_{4}+\gamma_{1} \mathrm{c}\right)
$$

This gives as before three cases. Case 2a is where both equalities hold. Both firms are indifferent between $\mathrm{T} 1$ and waiting. This case implies that $\mathrm{a}=\delta\left(1-\gamma_{1}\right)\left(\mathrm{U}_{2}-\mathrm{U}_{4}\right)$. As with case $1 \mathrm{a}$, it can be shown that the assumption of case $2 \mathrm{a}$ is inconsistent with the other assumptions made. Case $\mathbf{2 b}$ is where $a+\left(1-\gamma_{1}\right) c>\delta\left(\left(1-\gamma_{1}\right) U_{2}+\gamma_{1} c\right.$ and $(5 b)$ does hold. Firm 2 always proposes $T 2$ and firm 4 is indifferent. Firm 4 mixes between playing T2 and waiting. Case $2 \mathbf{c}$ is where (5a) holds and (1$\left.\gamma_{1}\right) c>\delta\left(\left(1-\gamma_{1}\right) U_{4}+\gamma_{1} c\right)$. Firm 2 is indifferent and firm 4 always proposes T2.

\section{Solving the competing committee game}

In equilibrium, in each committee both firms choose their strategies $\left(\alpha_{\mathrm{i}}\right)$ anticipating on how the resulting chance that they standardize, $\gamma_{\mathrm{j}}$, affects the other committee. The chance that either one or both committees set a standard in the period is 1-(1- $\left.\gamma_{1}\right)\left(1-\gamma_{2}\right)$, where $\gamma_{1}=\alpha_{1} \alpha_{3}$ and $\gamma_{2}=\alpha_{2} \alpha_{4}$. There are two pure outcomes. Committee 1 selects T1 immediately, i.e., $\gamma_{1}=1$. For committee 2 this means that the payoff of waiting is (c,c) and the payoff for selecting T2 is $(a, 0)$. Firm 4 has no incentive to adopt T2. Hence, committee 2 will wait, and $\gamma_{2}=0$. Anticipating this, committee 1 knows that selecting T1 is a dominant strategy: the payoffs are $(a+c, c)$ for $(T 1, T 1)$ and $\left(y_{1}, y_{3}\right)$ for the other actions (see table 1), where $\left(\mathrm{y}_{1}, \mathrm{y}_{3}\right)$ are the discounted payoffs of the next round, which are never higher than $(a+c, c)$. This outcome also holds in reverse, where committee 1 waits, and committee 2 proposes its preferred technology as standard.

To get around the existence of multiple pure equilibriums, we focus on symmetric mixed equilibriums. Combinations of cases $1 \mathrm{a}$ and $2 \mathrm{a}$ are not possible: there is no solution for the $\mathrm{y}_{\mathrm{i}}$ 's where conditions (2a) and (2b) both hold, and likewise for (3a) and (3b). Combinations of the cases $1 \mathrm{c}$ and $2 \mathrm{c}$ do exist that satisfy the equalities (2a) and (3a). However, it can be shown that these do not satisfy the 'greater than' conditions on (2b) and (3b).

Consistent solutions do appear for cases $1 \mathrm{~b}$ and $2 \mathrm{~b}$. In these cases, the sponsor in $\mathrm{a}$ committee (respectively, firm 1 or 2) always proposes its own technology as standard, and the other committee member (respectively, firm 3 or 4 ) mixes between either accepting the standard or waiting for another round. The allies are a mixed blessing to the sponsors: they help to turn a technology into a standard (a bandwagon effect), but they do slow down adoption of the technology. Straightforward but lengthy computations give the following solutions:

$$
\begin{aligned}
& U_{i}=\frac{c^{*}(1+\delta-\sqrt{1+(2-3 \delta) \delta})}{2 \delta}, \text { for } \mathrm{i}=3,4 . \\
& U_{i}=U_{j}+\frac{a}{1+\delta}, \text { for } \mathrm{i}=1,2, \text { and } \mathrm{j}=3,4 .
\end{aligned}
$$

Equation (4b) shows that the sponsors earn more than the followers, but by less than their appropriability bonus $a$. The reason is that there is a chance that the sponsor loses out to its rival. Moreover, part of the potential payoffs (a and c) are wasted because of the game play: the delays in decision making to prevent incompatibility from happening waste revenues. The total profits are:

$$
\sum_{i}^{4} U_{i}=\frac{2(a \delta+c(1+\delta)(1+\delta-\sqrt{1+(2-3 \delta) \delta}))}{\delta(1+\delta)}
$$

The chance that a committee selects its technology as standard is as follows: 


$$
\gamma_{i}=\frac{-1+\delta+\sqrt{1+(2-3 \delta) \delta}}{2 \delta}, \text { for } \mathrm{i}=1,2
$$

When the game ends, it is because either one or two standards are set in a period. The chance $z_{0}$ that no standard is agreed on in a period is $\left(1-\gamma_{1}\right)\left(1-\gamma_{2}\right)$. The chance $z_{1}$ that one standard is agreed on is $\gamma_{1}\left(1-\gamma_{2}\right)+\left(1-\gamma_{1}\right) \gamma_{2}$. The chance that two standards are agreed on simultaneously, $\mathrm{z}_{2}$, is $\gamma_{1} \gamma_{2}$. The chance that the game ends in a period is the chance that either one or two standards are set, $\mathrm{z}_{1}+\mathrm{z}_{2}$, which is $1-\left(1-\gamma_{1}\right)\left(1-\gamma_{2}\right)$, or:

$$
1-\frac{(1+\delta-\sqrt{1+(2-3 \delta) \delta})^{2}}{4 \delta^{2}} .
$$

We interpret this expression as the indicator for the speed of standardization. The chance that if the game ends, it ends with only one standard is $z_{1} /\left(z_{1}+z_{2}\right)$. This can be shown to be equal to the following expression:

$$
1-\frac{\sqrt{1-\delta}}{\sqrt{1+3 \delta}}
$$

We interpret this expression as the indicator for the expected degree of compatibility, associated with competing committees. Together, the expressions (7a) and (7b) locate the position of the competing coalitions in figure 1 . See figure 3 , which tracks (7a) and (7b) for values of the discount rate from 0 to 1 .

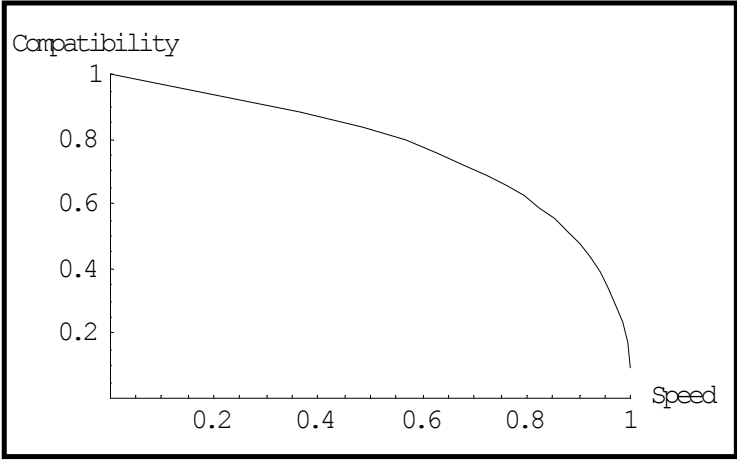

Figure 3: expected degree of compatibility of competing coalitions as function of expected speed

Figure 3 shows that increasing the speed of standardization reduces the chance that compatibility is achieved. The faster the standardization process is, the larger the chance that two committees select standards simultaneously, thus creating incompatibility. It also shows that a standardization mode with competing committees is capable of realizing compatibility with a high degree of probability, if at the cost of very slow standardization. A given coalition structure (here, two symmetric coalitions) can give rise to a large variety of outcomes, depending on the incentives and information of the decision makers. We now turn to the case where firms form a grand coalition to select an industry-wide standard. 


\section{Grand coalition}

In the grand coalition consensus among the four firms selects a standard. As before, firms 1 and 2 sponsor a technology as standard. Firms 3 and 4 benefit from a standard, but are indifferent about which technology becomes the standard. In a consensual decision making style, a technology is selected as standard if all four firm concur. If all firms were indifferent between T1 and T2, the chance that all four select the same technology as standard would be $(1 / 2)^{3}$, i.e., 0.125 . This would lead to very slow standardization. Moreover, firms 3 and 4 might identify different technologies as preferred standard, thus slowing down standardization, even though they are indifferent between both technologies. One way to speed up decision making would be to create a subcommittee of firms 1 and 2. They shall select a standard. Firms 3 and 4 will endorse whatever choice they make. ${ }^{8}$

This suggests that the game play in the grand coalition is between both sponsors. Their payoff matrix is as follows:

\begin{tabular}{|c|c|c|c|}
\hline & & & \\
\hline & & T1 & T2 \\
\hline Firm 1 & $\mathrm{~T} 1$ & $(a+c, c)$ & $\left(\mathrm{y}_{1}, \mathrm{y}_{2}\right)$ \\
\hline & T2 & $\left(\mathrm{y}_{1}, \mathrm{y}_{2}\right)$ & $(\mathrm{c}, \mathrm{a}+\mathrm{c})$ \\
\hline
\end{tabular}

The expected payoffs of this game are $U_{1}$ for firm 1 and $U_{2}$ for firm 2 . The payoffs $y_{1}$ and $y_{2}$ are the expected, discounted payoffs of playing the committee game in the next period: $y_{i}=\delta U_{i}$, where the discount rate $\delta$ is in between 0 and 1 (no discounting).

If we assume that $\mathrm{y}_{\mathrm{i}}<\mathrm{c}<\mathrm{a}+\mathrm{c}$, there are two pure Nash equilibriums: (T1, T1) and (T2, T2). We use the mixed equilibrium as solution concept. In a mixed equilibrium, each firm plays every possible action with a certain chance. Firm i $(=1,2)$ plays T1 with a chance of $\alpha_{i}$ and T2 with a chance of $1-\alpha_{i}$. This gives expected benefits as follows:

$$
\begin{aligned}
& \mathrm{U}_{1}=\alpha_{1} \alpha_{2}(\mathrm{a}+\mathrm{c})+\left(\left(1-\alpha_{1}\right) \alpha_{2}+\alpha_{1}\left(1-\alpha_{2}\right)\right) \mathrm{y}_{1}+\left(1-\alpha_{1}\right)\left(1-\alpha_{2}\right) \mathrm{c} \\
& \mathrm{U}_{2}=\alpha_{1} \alpha_{2} \mathrm{c}+\left(\left(1-\alpha_{1}\right) \alpha_{2}+\alpha_{1}\left(1-\alpha_{2}\right)\right) \mathrm{y}_{2}+\left(1-\alpha_{1}\right)\left(1-\alpha_{2}\right)(\mathrm{a}+\mathrm{c})
\end{aligned}
$$

In a mixed equilibrium, each firm chooses $\alpha_{\mathrm{i}}$ to keep his rival player indifferent between its two actions. Firm 1 chooses $\alpha_{1}$ such that for firm 2 the expected payoff of playing $\mathrm{T} 1, \alpha_{1}{ }^{*} \mathrm{c}+\left(1-\alpha_{1}\right)^{*} \mathrm{y}_{2}$, equals its expected payoff of playing T2, $\alpha_{1}^{*} \mathrm{y}_{2}+\left(1-\alpha_{1}\right) *(\mathrm{a}+\mathrm{c})$. This gives the following equation that solves for $\alpha_{1}$ :

$$
\alpha_{1}^{*} \mathrm{c}+\left(1-\alpha_{1}\right) * \mathrm{y}_{2}=\alpha_{1} \mathrm{y}_{2}+\left(1-\alpha_{1}\right) *(\mathrm{a}+\mathrm{c})
$$

Firm 2 chooses $\alpha_{2}$ such that firm 1 is indifferent between selecting T1 and T2:

$$
\alpha_{2} *(a+c)+\left(1-\alpha_{2}\right) * y_{1}=\alpha_{2} * y_{1}+\left(1-\alpha_{2}\right) * c .
$$

These computations give the solutions for both chances $\alpha_{1}$ and $\alpha_{2}$, as functions of the payoffs in table 3.

\footnotetext{
${ }^{8}$ See footnote 4 why we rule out the case where firms 3 and 4 set up a subcommittee, select a standard, and impose it on the sponsors, firms 1 and 2.
} 
The other two firms, 3 and 4, adopt whatever standard firms 1 and 2 propose. Their expected payoffs are as follows:

$$
\mathrm{U}_{\mathrm{i}}=\left(\alpha_{1} \alpha_{2}+\left(1-\alpha_{1}\right)\left(1-\alpha_{2}\right)\right) \mathrm{c}+\left(\left(1-\alpha_{1}\right) \alpha_{2}+\alpha_{1}\left(1-\alpha_{2}\right)\right) \mathrm{y}_{\mathrm{i}}, \text { where } \mathrm{y}_{\mathrm{i}}=\delta \mathrm{U}_{\mathrm{i}}(\mathrm{i}=3,4)
$$

The chance that the grand coalition selects a standard within a time period is $\left(\alpha_{1} \alpha_{2}+\left(1-\alpha_{1}\right)\left(1-\alpha_{2}\right)\right)$.

The results of this model are unfortunately very cumbersome. The sum total of expected payoffs are as follows:

$$
\Sigma_{1}^{4} \mathrm{U}_{\mathrm{i}}=\frac{\mathrm{Ha}+4 \mathrm{CL} \mathrm{I}-\mathrm{a}-2 \mathrm{C}+{ }^{\grave{\mathrm{e}}} \overline{\mathrm{Ha}+2 \mathrm{CL}^{2}+4 \mathrm{c} \mathrm{Ha}+\mathrm{CL} \mathrm{H}-2+\delta \mathrm{L} \delta \mathrm{M}}}{\mathrm{Ha}+2 \mathrm{CL} \mathrm{H}-2+\delta \mathrm{L} \mathrm{\delta}}
$$

The indicator for the speed of standardization by the grand coalition is the chance that it sets a standard within a period:

$$
\begin{aligned}
& \mathrm{H}-1+\delta \mathrm{L} \mathrm{I} \mathrm{a}^{2}-4 \mathrm{ac}-4 \mathrm{c}^{2}+4 \mathrm{ac} \delta+4 \mathrm{c}^{2} \delta-\mathrm{Ha}+2 \mathrm{cL} \text { è } \overline{\mathrm{Ha}+2 \mathrm{CL}^{2}+4 \mathrm{cHa}+\mathrm{CL} \mathrm{H}-2+\delta \mathrm{L} \delta} \mathrm{M} \\
& \mathrm{I}-\mathrm{Ha}+2 \mathrm{CL} \mathrm{H}-1+\delta \mathrm{L}+{ }^{\mathrm{è}} \overline{\mathrm{Ha}+2 \mathrm{CL}^{2}+4 \mathrm{CHa}+\mathrm{CL} \mathrm{H}-2+\delta \mathrm{L} \delta} \mathrm{M}^{2}
\end{aligned}
$$

The derivative of expression (11) to the appropriability bonus $a$ is the following expression:

$$
\begin{aligned}
& 2 \mathrm{aCH}-2+\delta \mathrm{L}^{2} \mathrm{H}-1+\delta \mathrm{L} \\
& \overline{\mathrm{e}} \overline{\mathrm{Ha}+2 \mathrm{CL}^{2}+4 \mathrm{CHa}+\mathrm{CL} \mathrm{H}-2+\delta \mathrm{L} \delta} \mathrm{I} \mathrm{a}-2 \mathrm{CH}-1+\delta \mathrm{L}-\mathrm{a} \delta+\stackrel{\mathrm{e}}{\overline{\mathrm{Ha}+2 \mathrm{CL}^{2}+4 \mathrm{CHa}+\mathrm{CL} \mathrm{H}-2+\delta \mathrm{L} \delta} \mathrm{M}^{2}}
\end{aligned}
$$

Since $\delta<1$, it follows that this expression is negative. A higher appropriability bonus slows down the grand coalition: it makes the competing sponsors more eager on proposing their preferred technology as standard. The derivative to $c$ can be shown to be positive: if the compatibility bonus increases relative to the appropriability bonus, this speeds up the grand coalition.

\section{Comparing the grand coalition to the competing committees}

We will compare the results of the grand coalition and the case with competing committees. There are three indicators to look at: the total profits $\left(\Sigma_{1}^{4} U_{i}\right)$, the profits of a sponsor $\left(U_{1}\right)$, and the chance that a standard (or two standards) is selected within the period. The latter indicator determines the speed of standardization: the higher the selection chance is, the higher the expected speed of standardization.

Equation (12) shows that a higher appropriability bonus slows down the grand coalition, and a higher compatibility bonus speeds up the grand coalition. Equation (7a) shows that the appropriability bonus and the compatibility bonus do not have this effect on the competing committees. Hence, we derive the following proposition:

Proposition 1: an increasing appropriability bonus tends to slow down a grand coalition, while an increasing compatibility bonus tends to speed it up, compared with a case of competing committees.

Due to the rather cumbersome equations, we use numerical simulation for further results. We will call $e$ the ratio of the appropriability bonus to the compatibility bonus: $\mathrm{e}=\mathrm{a} / \mathrm{c}$, where $\mathrm{e}>0$. The 
relative speed of standardization by a grand coalition compared to competing committees can be deduced from the difference in the chance that a standard is set within a time period. The following expression gives this differential:

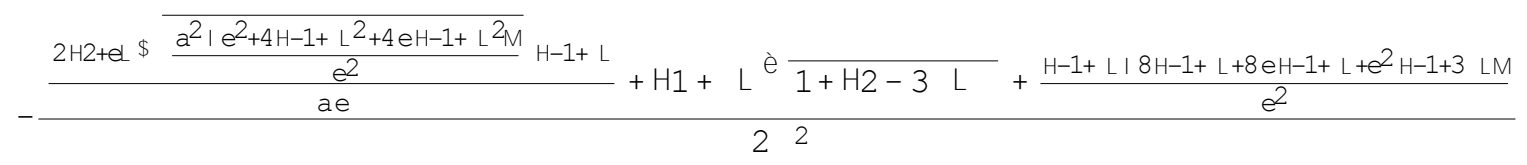

Inspection shows that the appropriability bonus $a$ can be factored out. Hence, the relative speed of the grand coalition versus competing committees depends only on $e$ and on $\delta$. For a discount factor equal to one, this value equals zero. With such a high discount rate, the standardization process in both standardization modes grinds to a halt. Both sponsors are eager to impose their own technology as standard, and this intransigence delays standardization. If the discount rate is unity, the delay does not reduce their discounted revenues.

Simulation gives the following results, see table 4 . From left to right the columns have increasing values of $\delta$ from 0.1 to 0.9 in steps of 0.2 . Each column list values from $\mathrm{e}=0.000001$ at the top to $\mathrm{e}=2$ at the bottom, in steps of 0.2 .

\begin{tabular}{|lllll|}
\hline-0.390625 & -0.43674 & -0.352539 & -0.223713 & 0.0149951 \\
-0.496196 & -0.446251 & -0.363286 & -0.242527 & -0.0756781 \\
-0.507021 & -0.460372 & -0.384114 & -0.281289 & -0.179908 \\
-0.52108 & -0.478394 & -0.409658 & -0.323517 & -0.247362 \\
-0.536643 & -0.497939 & -0.436165 & -0.362557 & -0.291605 \\
-0.552702 & -0.51768 & -0.461797 & -0.396676 & -0.322338 \\
-0.568672 & -0.536902 & -0.485754 & -0.425956 & -0.34479 \\
-0.584219 & -0.555238 & -0.507767 & -0.451007 & -0.361862 \\
-0.599162 & -0.572526 & -0.52783 & -0.472512 & -0.375263 \\
-0.613411 & -0.588716 & -0.546055 & -0.491084 & -0.386051 \\
\hline
\end{tabular}

Table 4: Speed differential between the grand coalition and competing committees

The speed differential is nearly everywhere negative. The grand coalition tends to standardize slower than competing committees. Along a row (for a given level of $e$ ), higher values of $\delta$ reduce the speed disadvantage of the grand coalition. The reason is that the more important future revenues are (the higher $\delta$ ), the less important it is for competing committees to set a standard quickly, at the risk of selecting competing technologies and wasting future revenues. Along a column, the higher $e$ is, the larger the speed disadvantage of the grand coalition. The higher the appropriability bonus $a$ is relative to the compatibility bonus $c$, the more the sponsors insist on their technology becoming standard, the slower the grand coalition is. The appropriability bonus leads to politicking in the grand coalition. It should now be intuitive why in the table the grand coalition tends to be quicker than competing committees only in the right upper corner of table 4 , where $e$ is very low (0.000001) and $\delta$ is very high (0.9).

The choice between a grand coalition and competing committees recognizes a trade-off. The competing committees tend to be quicker. The grand coalition, however, ensures compatibility of the four firms, whereas the competing committees may lead to incompatible technologies being selected. Expression (7b) shows that for $\delta<1$, the chance that the competing committees set a single standard is less than unity. Apart from the case of very high $\delta$ 's, there is thus a trade-off between speed and compatibility. 
Figure 4 illustrates the trade-off between speed and compatibility. It shows the expected speed and compatibility for the competing committees and for the grand coalition for $\mathrm{a}=1, \mathrm{e}=1$, and $\delta=0.5$. The chance that the grand coalition establishes only one standard (compatibility) is unity. The left most point is for the grand coalition; the point on the right is for the competing committees. The larger $\delta$ is, the closer these points lie together, and the more they shift to the top left side of the graph (high compatibility, slow speed).

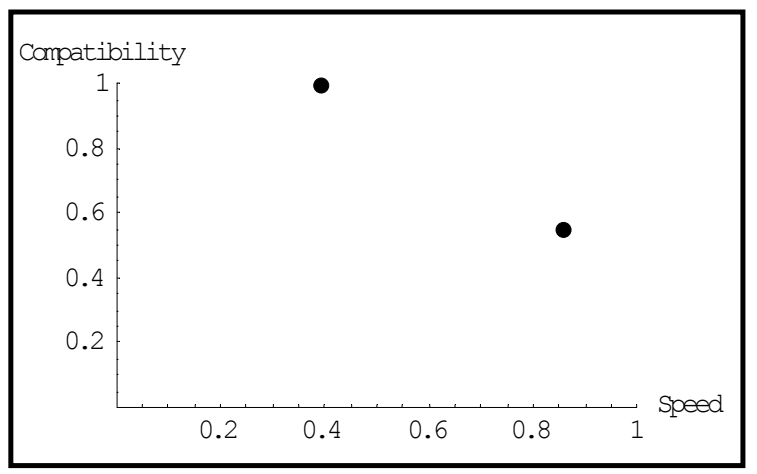

Figure 4: the expected speed and compatibility

Given the trade-off between speed and compatibility, the question is which type of coalition structure will the firms prefer? If we look at firm 1, one of the two sponsors in the game, will it prefer a grand coalition or competing committees? The difference between the payoff of firm 1 in the case of the grand coalition and its profit in the case of competing committees is the following expression (where again $\mathrm{e}=\mathrm{a} / \mathrm{c}$ ):

$$
e \$ \overline{\frac{a^{2} I e^{2}+4 H-1+\delta L^{2}+4 e H-I+\delta L^{2} M}{e^{2}}} H I+\delta L+a H-2+\delta L H 1+\delta L \text { è } \overline{1+H 2-3 \delta L \delta}-a H-1+\delta L H-e+\delta+2 e \delta+\delta^{2} L
$$

2 e $\mathrm{H}-2+\delta \mathrm{L} \delta \mathrm{H} 1+\delta \mathrm{L}$

Visual inspection shows that this expression is a multiple of $a$. The sign depends on two variables only: e and $\delta$. We know that $0<\mathrm{e}$ and $0<\delta<1$. We simulate this for values of e and $\delta$. See table 5 .

\begin{tabular}{|lllll|}
\hline 3.68727 & 2.94451 & 2.4899 & 2.19469 & 1.72987 \\
0.76668 & 0.624049 & 0.551263 & 0.504586 & 0.319265 \\
0.167927 & 0.141511 & 0.1389 & 0.131386 & 0.00128769 \\
-0.0967497 & -0.0751943 & -0.0502989 & -0.0435628 & -0.142398 \\
-0.248722 & -0.201457 & -0.162338 & -0.147831 & -0.224504 \\
-0.348652 & -0.285521 & -0.237751 & -0.217839 & -0.277664 \\
-0.420042 & -0.346186 & -0.292537 & -0.268348 & -0.314898 \\
-0.473963 & -0.392376 & -0.334399 & -0.306605 & -0.342433 \\
-0.516346 & -0.42891 & -0.367556 & -0.336627 & -0.363621 \\
-0.550668 & -0.458638 & -0.394533 & -0.360832 & -0.380431 \\
\hline
\end{tabular}

Table 5: $\mathrm{U}_{1}$ of grand coalition minus $\mathrm{U}_{1}$ of competing committees 
Each column in table 5 is associated with one value of $\delta$. From left to right the columns have increasing values of $\delta$ from 0.1 to 0.9 in steps of 0.2 . Each column list values from $\mathrm{e}=0.1$ at the top to $\mathrm{e}=2$ at the bottom in steps of 0.2. Positive values in the table indicate cases where firm 1 will prefer the grand coalition; negative values cases where it prefers competing committees. For a given $\delta$, an increasing value of $e$ (along a column) changes sign from positive to negative: when the appropriability bonus $a$ becomes more important than the compatibility bonus $c$, firm 1 switches from preferring a grand coalition to preferring competing committees. There seems no large effect of the discount rate on the preference for a grand coalition: the sign of the profit difference does not change in the discount rate $\delta$ for each value of $e$ (along the rows).

We can also compute the difference between total profits with the grand coalition and with competing committees. Again, this is a complicated function:

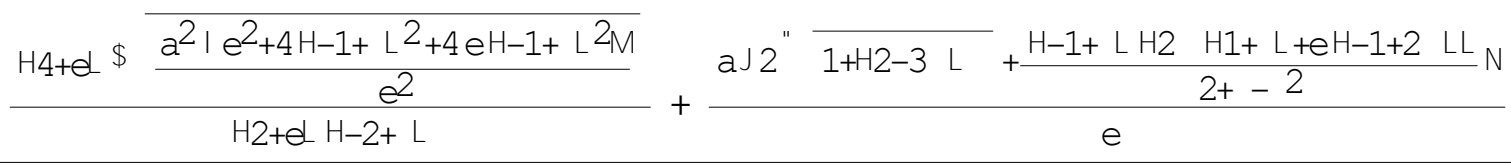

$$
\begin{aligned}
& \delta
\end{aligned}
$$

The parameter $a$ can be bracketed out, which shows that the sign of the difference depends only on $e(=\mathrm{a} / \mathrm{c})$ and on the discount rate $\delta$. For $\delta=1$, this expression can be simplified into $-\frac{a(4+e)}{2+e}$. Hence, for a discount rate of unity, the total expected profits with a grand coalition are less than those with competing committees. For a simulation (where $a=1$, without impact on the sign of the profit differential), see table 6 .

\begin{tabular}{|lllll|}
\hline 16.0422 & 12.7299 & 10.6285 & 9.18978 & 7.07379 \\
4.36803 & 3.45852 & 2.88852 & 2.45282 & 1.48508 \\
1.98574 & 1.54455 & 1.26114 & 0.993802 & 0.272641 \\
0.942063 & 0.696648 & 0.529602 & 0.330572 & -0.247603 \\
0.350187 & 0.211552 & 0.107524 & -0.0505907 & -0.52763 \\
-0.0333022 & -0.104688 & -0.168493 & -0.29675 & -0.697472 \\
-0.302857 & -0.327816 & -0.363079 & -0.46741 & -0.808457 \\
-0.503023 & -0.493818 & -0.507331 & -0.591606 & -0.884784 \\
-0.657657 & -0.622107 & -0.618216 & -0.685273 & -0.939261 \\
-0.780736 & -0.72414 & -0.705835 & -0.757892 & -0.979249 \\
\hline
\end{tabular}

Table 6: Difference between $\Sigma_{1}{ }^{4} U_{\mathrm{i}}$ of the grand coalition and the competing committees

The results are similar as in the case of profits of firm 1 alone. The larger $e$ is (within a column), the more likely that the collective of firms will prefer competing committees to the grand coalition. Hence, if the appropriability bonus $a$ increases relative to the compatibility bonus $c$, this tends to shift preferences away from the grand coalition to competing committees.

\section{Conclusions}

This paper shows that having an industry-wide standardization coalition tends to slow down standardization, compared to cases where smaller coalitions of firms compete with each other. This is consistent with a widely held view. The need to reach an agreement between competitors within a grand coalition leads to lengthy negotiations. If sponsors of rival technologies set up 
their own coalitions, this should speed up standardization. Competition between standardization coalitions does, however, squander some benefits of having a standard. In choosing a standardization mode, firms balance two types of coordination failure: the failure to select an industry-wide standard (when competing committees support competing technologies) and the failure to decide timely (when negotiations in a grand coalition lead to stalemate).

Consistent with an argument by Genschel (1997), competing coalitions do not have to lead to incompatible technologies. If one committee adopts a standard before the other one, the latter will concede defeat and adopt this standard too. Incompatibility only happens in our model when the two committees select a standard simultaneously. This can occur with a certain chance. By reducing the chance that firms in a coalition select a technology as standard in a given time period, the smaller the chance that both committees select a standard at the same time. This does slow down the standardization process, however. Competing committees can thus reduce one coordination failure (the failure to select a single standard) by somewhat increasing another coordination failure (of delaying decision making in a committee).

The paper also shows that the speed disadvantage of a grand coalition should not be exaggerated. Firstly, our results are expectations: a string of luck may lead to quick decision making in a grand coalition, whereas as competing coalitions may get stuck in multiple rounds of fruitless negotiations. The expected speed disadvantage may also be limited. In fact, we find cases where a grand coalition can be quicker than competing coalitions. The reason is that competing coalitions may select incompatible technologies as standards. To avoid this, firms delay standard selection within the committees. The slower the committees decide about a standard, the smaller the chance that they simultaneously adopt incompetence technologies. The fear for incompatibility thus delays competing coalitions, and may render the grand coalition the quickest solution.

The more sponsors of rival technologies stand to gain from having their technology selected as standard (the appropriability bonus $a$ ), the more they tend to prefer competing committees. The more they value future revenues (indicated by the discount rate $\delta$ ), the more they prefer a grand coalition. Short time horizons and high rates of uncertainty thus tend to stimulate fragmentation of the standardization process. If committees, including the grand coalition, can meet frequently, this shortening of the decision time period translates in our model as a high discount rate. This in turn will increase the preference for a grand coalition. If both small committees and the grand coalition were to speed up the frequency of their meetings in equal measure, this would shift the preference towards the grand coalition.

An insight that modelling standardization may give is that the effects of coalition structures on compatibility and speed of decision making depend on the behaviour of firms within these structures. A given structure, such as competing committees, can lead to widely varying outcomes, depending on incentives (see figure 3 for an illustration). These incentives depend on goals, information, and also on how decision making in the coalition(s) is structured. Both competing committees and the grand coalition benefit from structuring decision making such as to speed up decision-making. In the case of competing committees this calls for a proper selection of coalition members. By keeping rivals out of a committee, a sponsor of a technology can convince its coalition to relatively quickly select its technology as standard. The downside of this strategy is that the rival creates its own coalition, and their standard may undercut one's standardization efforts. In the grand coalition, the problem is how to align a large number of firms behind one standard. Even in the absence of conflicts of interest, this may take time. All the more so when rivals populate the grand coalition. In designing a standardization mode, one should not try to avoid coordination failures between coalitions, without understanding the intra-coalition coordination failures. Addressing intra-coalition coordination failures appears the prior step, before attempting to create industry-wide structures of decision-making. 


\section{References}

Axelrod, R., Mitchell, W., Thomas, R. E., Bennett, D. S., \& Bruderer, E. (1995). Coalition Formation in Standard-setting Alliances. Management Science, 41(9), 1493-1508.

Belleflamme, P. (1998). Adoption of network technologies in oligopolies. International Journal of Industrial Organization, 16, 415-444.

Besen, S. M., \& Farrell, J. (1994). Choosing how to Compete: Strategies and Tactics in Standardization. Journal of Economic Perspectives, 8(2), 117-131.

Blind, K. (2001). The Impact of Intellectual Property Rights on the Propensity to Standardise at Standardisation Development Organisations: An Empirical International Cross-Section Analysis.Unpublished manuscript.

Bloch, F. (1995). Endogenous structures of association in oligopolies. RAND Journal of Economics, 26(3), 537-556.

Choi, J. P. (1996). Do converters facilitate the transition to a new incompatible technology? A dynamic analysis of converters. International Journal of Industrial Organization, 14(6), 825-835.

Cowan, R., \& Miller, J. H. (1998). Technological standards with local externalities and decentralized behaviour. Journal of Evolutionary Economics, 8, 285-296.

David, P. A., \& Shurmer, M. (1996). Formal Standards-setting for Global Telecommunications and Information Services: Towards an Institutional Regime Transformation? Telecommunications Policy, 20(10), 789-815.

Economides, N., \& Flyer, F. (1998). Equilibrium coalition structures in markets for network goods. Annales d'Economie et de Statistique(49/50), 361-380.

Farrell, J., \& Saloner, G. (1988). Coordination through committees and markets. RAND Journal of Economics, 19(2), 235-252.

Funk, J. L., \& Methe, D. T. (2001). Market- and committee-based mechanisms in the creation and diffusion of global industry standards: the case of mobile communication. Research Policy, 30, 589-610.

Genschel, P. (1997). How fragmentation can improve co-ordination: setting standards in international telecommunications. Organization Studies, 18(4), 603-622.

Greenlee, P., \& Cassiman, B. (1999). Product market objectives and the formation of research joint ventures. Managerial and Decision Economics, 20, 115-130.

Gulati, R. (1995). Social Structure and Alliance Formation Patterns: A Longitudinal Analysis. Administrative Science Quarterly, 40, 619-652.

Heywood, P., Jander, M., Roberts, E., \& Saunders, S. (1997). Standards, The Inside Story: Do Vendors have too much Influence on the Way Industry Specs are Written and Ratified? Data Communications, 59-72.

Katz, M. L., \& Shapiro, C. (1985). Network Externalities, Competition, and Compatibility. American Economic Review, 75(3), 424-440.

Katz, M. L., \& Shapiro, C. (1992). Product Introduction with Network Externalities. The Journal of Industrial Economics, 40(1), 55-83.

Mangematin, V., \& Callon, M. (1995). Technological competition, strategies of the firms and the choice of the first users: the case of road guidance technologies. Research Policy, 24(3), 441-458.

Sherif, M. H. (2003). When is Standardization Slow? Journal of IT Standards \& Standardization Research, 1(1), 19-32.

Shy, O. (1996). Technology revolutions in the presence of network externalities. International Journal of Industrial Organization, 14(6), 785-800.

Wallace, J. (1997). Overdrive: Bill Gates and the Race to Control Cyberspace. New York: John Wiley \& Sons. 
Zajac, E. J., \& Olsen, C. P. (1993). From transaction cost to transactional value analysis: implications for the study of interorganizational strategies. Journal of Management Studies, 30(1), 131-145. 